\title{
LIMA 01
}

\section{Philippe Gruenberg}

Lima (1972). Estudios de Filosofía y Economía, London School of Economics and Political Science, 1993-1995 y estudios de Fotografía, Centre pour l'Image Contemporain SaintGervais, Ginebra, 1995 e Instituto Antonio Gaudí, Lima, 1997-1998. Fue cofundador del colectivo artístico Espacio La Culpable en 2002 y codirector de la Galería del Escusado en Lima (2002-2003).

Su trabajo ha sido expuesto en Lima, Santiago, São Paulo y Munich, entre otras ciudades. Actualmente vive en Lima.

\section{Pablo Hare}

ima (1972). Estudios de Comunicaciones en la Universidad de Lima, 1990-1994; de Fotografía en el Instituto Antonio Gaudí, Lima,1994-1996 y de Cinematografía en la Escuela Internacional de Cine y Televisión de San Antonio de los Baños, Cuba, 1997-1999. Fue cofundador del colectivo artístico Espacio La Culpable en 2002 y codirector de la Galería del Escusado en Lima (2002-2003).

Su trabajo ha sido expuesto en Lima, París, Santiago, São Paulo y La Habana, entre otras ciudades. En 2008 fundó la editorial Toromuerto Press y actualmente vive en Bristol.
$\mathbf{E}$ n Lima, el último real intento de planificación urbana -en base a las afrancesadas perspectivas tomadas del reordenamiento del París napoleónico, a manos del Barón Haussmann- sucedió a fines del xIx, bajo el trunco gobierno del Presidente Piérola. En esa ocasión, sin embargo, la administración de una crisis política más fuerte que los anhelos de cierta modernización expresados en el diseño de la ciudad, hizo que aquellos quedaran igualmente truncos y no fueran terminados sino ya avanzado el siglo $\mathrm{xx}$, con otras crisis y otros parecidos administradores en el horizonte. El alcance de esa modernización y de esas perspectivas, sin embargo, es visible en el área reducida que ocupa esa planificación. Si bien varias de esas ampliaciones expresadas primero en bulevares virtuales, alamedas boscosas y pequeñas avenidas fueron el espacio privilegiado de una Lima con anhelos de patriciado burgués, no hay que caminar muy lejos para dar cuenta del carácter paradigmáticamente simulado de esa modernización. Abruptamente cortadas como un sueño, esas avenidas y perspectivas de elegancia afrancesada acabaron frente a frente a los muladares, callejones y rancheríos que ocuparon la servidumbre y la plebe ciudadana expulsadas del diseño urbano. Una superficial arqueología urbana daría perfectamente cuenta del carácter de esa transformación que, como el set de un viejo western, hizo de las fachadas y de los falsos agregados y dinteles un arte en sí mismo, y del corazón de la quincha y el barro colonial, la armazón estructural de todo ese pretendido afrancesamiento, una metáfora perfecta de la verdadera orientación de la ciudad en materia de crecimiento. El verosímil pequeño flâneur benjaminiano de estas avenidas limeñas conoció sin duda la estrechez de esta brevísima experiencia urbana.

Ese diseño incluyó de manera perdurable también la convivencia del lujo y la precariedad, una característica que va más allá de cualquier explicación atribuible al subdesarrollo o a la tercermundización de las realidades. En el fondo, el diseño urbano de estas características implica la expectativa de un espacio ideal, que es el del espacio público convertido en recinto privado de sus habitantes más poderosos. Si el rancherío y el callejón (dos versiones locales de la tugurización) convivieron hasta muy entrado el siglo xx con la casona $\mathrm{y}$ la mansión, se debió a que las relaciones del paternalismo hicieron necesarias las proximidades de la servidumbre. Esas relaciones se verían alteradas más adelante con la incipiente incorporación del trabajador asalariado urbano en la posguerra. Sin embargo, la otra institución urbana de la empleada doméstica cama adentro emula un rezago de esas relaciones, en las que toda conquista laboral moderna de horarios y respectivos salarios queda suspendida por pertenecer al universo de lo privado y en donde el servicio doméstico se encuentra, literalmente, al alcance de la mano. En la actualidad ese modelo subsiste de algún modo en las virtuales cités dortoirs que en algún momento fueron las ciudadelas marginales que rodean Lima y en los barrios obreros que cohabitan junto a los residenciales. A diferencia de Santiago o Buenos Aires, atravesar Lima es imposible sin pasar de una isla de abundancia a otra de necesidad. La ciudad es en ese sentido un archipiélago polarizado en el que pobreza y riqueza conviven en ese diseño, porque su puesta en acción asegura la invisibilidad de la otredad de la pobreza o de la subalternidad y Lima, más que ninguna otra capital del hemisferio, ha sabido crecer con esa tipología incorporada.

Los edificios horadados por el trabajo fotográfico de Gruenberg y Hare fueron construidos en la posguerra y pertenecen al horizonte de relativa prosperidad comercial que, luego de algunos terremotos, deshizo también el paisaje histórico colonial de la ciudad con avenidas anchas, e incluso trasplantó casonas coloniales hacia otras zonas de crecimiento urbano, en donde fueron simbólicamente reubicadas, mientras el concreto hacía lo suyo en la transformación de la ciudad. Los nombres de muchos de estos edificios llevan los reconocibles apellidos de familias de exitosos comerciantes, que fueron reemplazando los más viejos apellidos vinculados a la pretendida aristocracia que vivió en las casonas desplazadas, o si prefiere, meramente reemplazadas. Pero si estos edificios, antes lujosos, son ahora susceptibles de transformarse en cámaras oscuras, es porque fueron paulatinamente abandonados a partir de 1970, lo que coincidió con la masificación abierta de las calles. Como a las puertas de un castillo cerrado, la calle asumió entonces el espacio de la heterogeneidad y del conflicto de la sociedad generada por la migración del campo a la ciudad, y fue el escenario desnudo de individuos masivamente orientados por la búsqueda de ciudadanía.

En la serie de Gruenberg y Hare, la imagen de la ciudad ha invadido efímeramente las oscuras paredes de estos recintos privados y cerrados sobre sí mismos frente a una calle masificada, y lo que vemos realmente en la serie es el registro en placas de la exposición de estos edificios a la ciudad (aunque en el proyecto original, la idea era emulsionar papel fotográfico colocado en las paredes). De este modo, la ciudad interviene y deshace la fantasmagoría del interior de la que hablaba Benjamin, refiriéndose al fetiche del universo privado. Una fantasmagoría intervenida aquí por otra, en realidad, que es la del espectro de luz que ingresa por el pequeño orificio del pinhole.

Rodrigo Quijano Extracto de La ciudad: el camello por el ojo de la aguja, 2002.

La serie de once fotografías de Lima o1 está disponible para suscriptores ARQ en edicionesarq.cl 


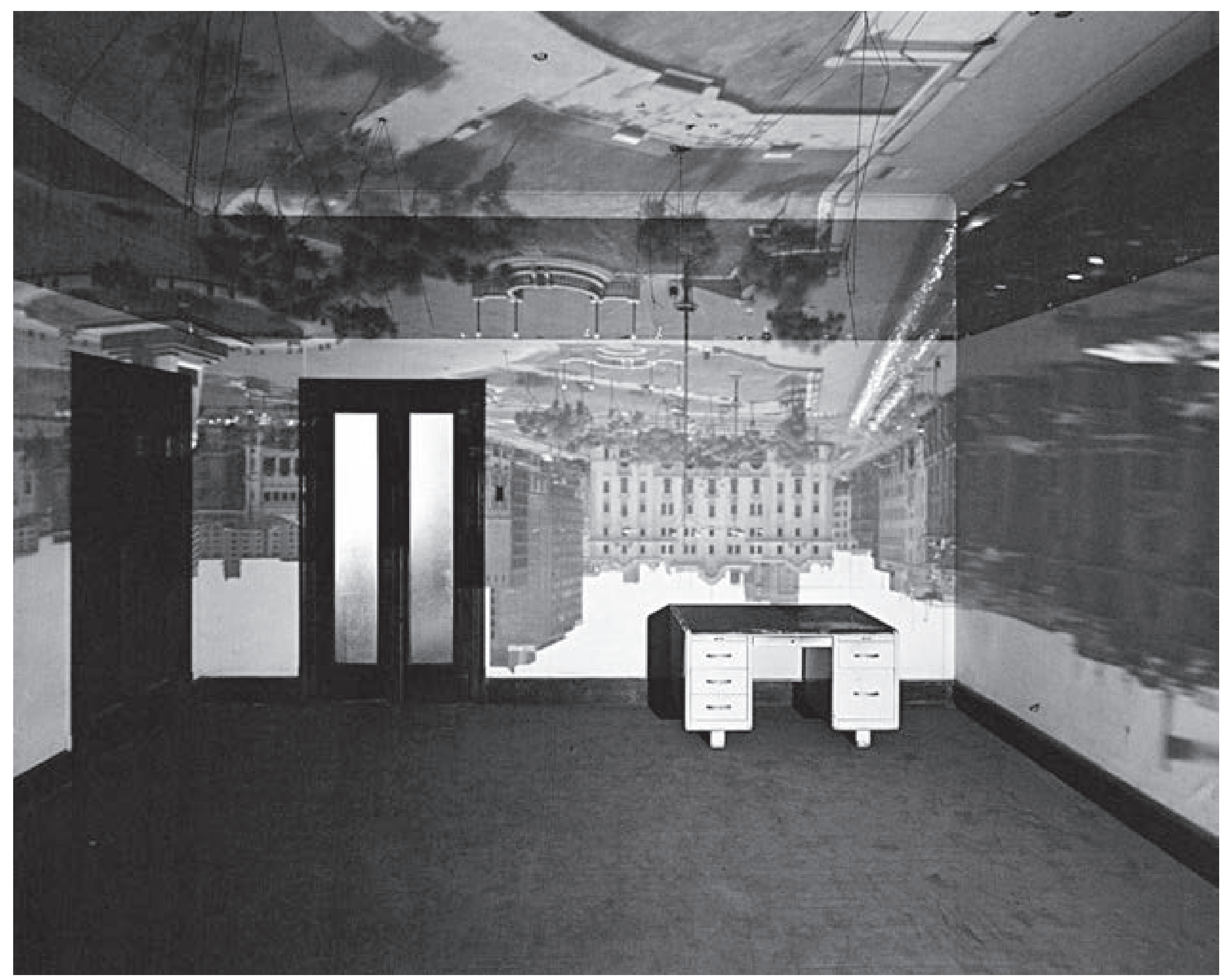




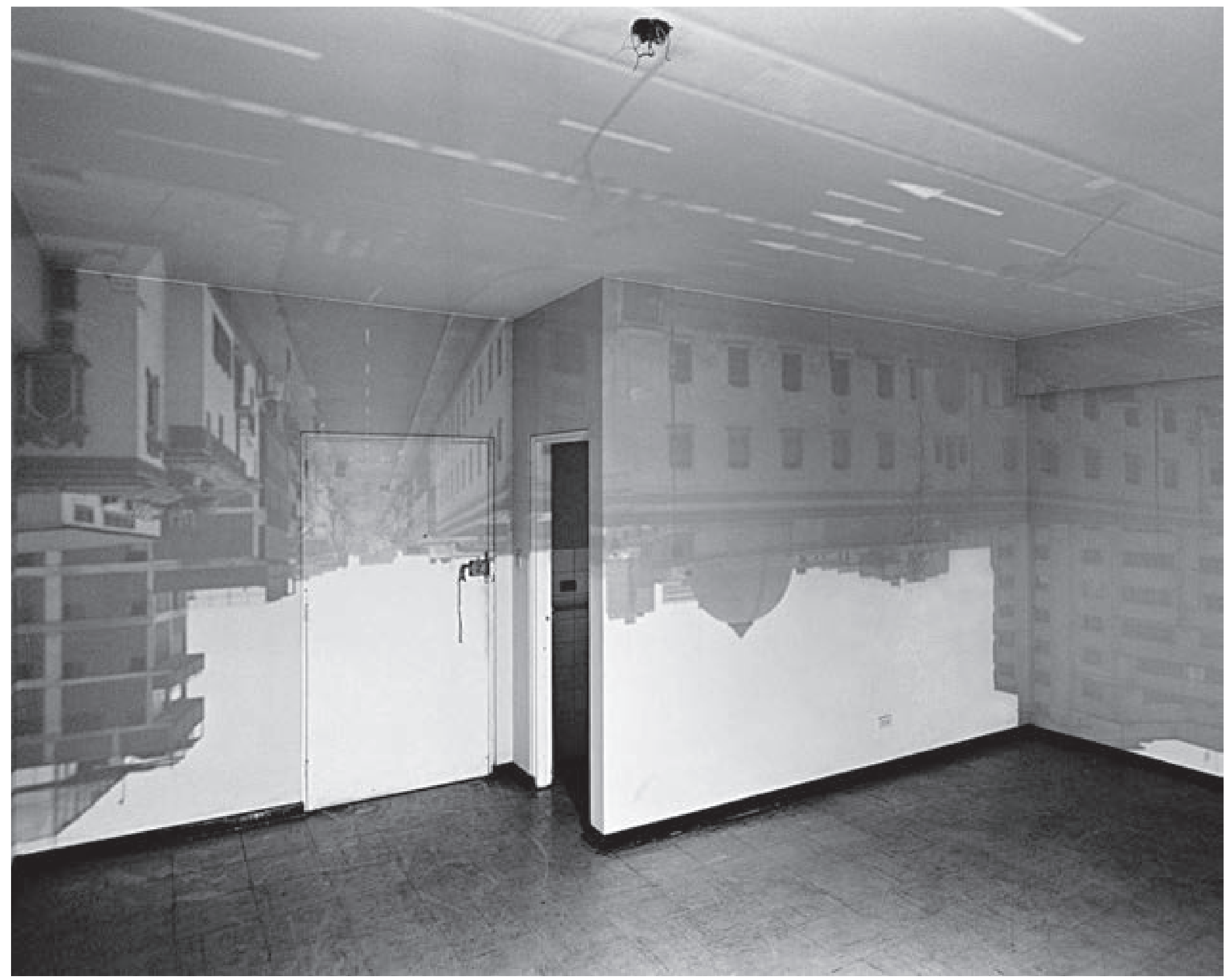




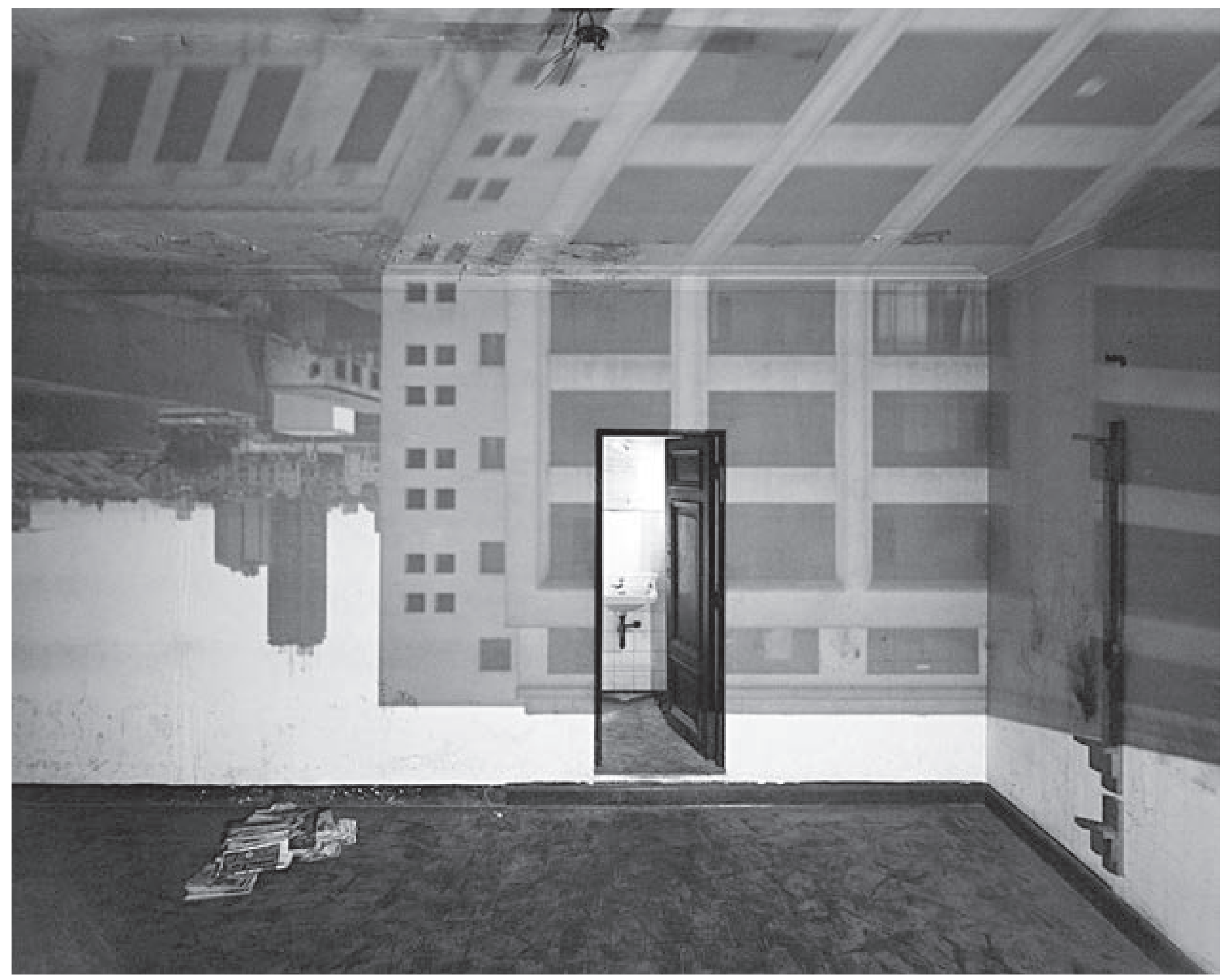

